University of Wollongong

Research Online

Faculty of Engineering and Information

Faculty of Engineering and Information

Sciences - Papers: Part A

Sciences

$1-1-2015$

\title{
Application of optical-Fiber Bragg Grating sensors in monitoring the rail track deformations
}

\author{
S.K. Karimullah Hussaini \\ Indian Institute of Technology-Patna \\ Buddhima Indraratna \\ University of Wollongong, indra@uow.edu.au \\ Jayan S. Vinod \\ University of Wollongong, vinod@uow.edu.au
}

Follow this and additional works at: https://ro.uow.edu.au/eispapers

Part of the Engineering Commons, and the Science and Technology Studies Commons

Research Online is the open access institutional repository for the University of Wollongong. For further information contact the UOW Library: research-pubs@uow.edu.au 


\title{
Application of optical-Fiber Bragg Grating sensors in monitoring the rail track deformations
}

\author{
Abstract \\ The lateral flow of ballast during the passage of trains can reduce the stability of rail tracks. Therefore, it \\ is important to monitor and restrain the movement of ballast accordingly in order to prevent track \\ misalignment. This current study explored the use of optical-Fiber Bragg Grating (FBG) sensors to \\ measure the lateral displacement of unreinforced and geogrid-reinforced ballast. The tests were \\ conducted on fresh latite basalt at a loading frequency of $20 \mathrm{~Hz}$ and up to 250000 load cycles. The test \\ results showed that the FBG sensing system is fully capable of measuring the lateral displacement of \\ ballast under high-frequency cyclic loading. A comparison of strains obtained from FBGs installed at \\ different depths along the ballast depth is made and the lateral strain profiles are measured. Moreover, an \\ empirical model to convert the FBG strains to an equivalent lateral displacement of ballast is proposed to \\ effectively use this technology in real-time monitoring of track deformations.

\section{Disciplines} \\ Engineering | Science and Technology Studies

\section{Publication Details} \\ Hussaini, S., Indraratna, B. \& Vinod, J. S. (2015). Application of optical-Fiber Bragg Grating sensors in \\ monitoring the rail track deformations. Geotechnical Testing Journal, 38 (4), 387-396.
}




\section{Geotechnical Testing Journal}

doi:10.1520/GTJ20140123 / Vol.38 / No.4 / July 2015 / available online at www.astm.org

Manuscript received June 15, 2014; accepted for publication April 20, 2015; published online May 8, 2015.

'Assistant Professor, Department of Civil and Environmental Engineering, Indian Institute of Technology Patna, Bihar-800013, India, e-mail: hussaini@iitp.ac.in; Formerly Ph.D. Candidate at Centre for Geomechanics and Railway Engineering, Univ. of Wollongong, Wollongong City, NSW 2522, Australia.

${ }^{2}$ Professor of Civil Engineering and Research Director, Centre for Geomechanics and Railway Engineering; Univ. of Wollongong, Wollongong City, NSW 2522, Australia (Corresponding author), e-mail: indra@uow.edu.au

${ }^{3}$ Senior Lecturer in Civil Engineering, Centre for Geomechanics and Railway Engineering, Univ. of Wollongong, Wollongong City, NSW 2522, Australia, e-mail: vinod@uow.edu.au
S. K. Karimullah Hussaini, ${ }^{1}$ Buddhima Indraratna, ${ }^{2}$ and Jayan S. Vinod ${ }^{3}$

\section{Application of Optical-Fiber Bragg Grating Sensors in Monitoring the Rail Track Deformations}

\section{Reference}

Hussaini, S. K. Karimullah, Indraratna, Buddhima, and Vinod, Jayan S., "Application of Optical-Fiber Bragg Grating Sensors in Monitoring the Rail Track Deformations," Geotechnical Testing Journal, Vol. 38, No. 4, 2015, pp. 387-396, doi:10.1520/GTJ20140123. ISSN 0149-6115

\section{ABSTRACT}

The lateral flow of ballast during the passage of trains can reduce the stability of rail tracks. Therefore, it is important to monitor and restrain the movement of ballast accordingly in order to prevent track misalignment. This current study explored the use of optical-Fiber Bragg Grating (FBG) sensors to measure the lateral displacement of unreinforced and geogrid-reinforced ballast. The tests were conducted on fresh latite basalt at a loading frequency of $20 \mathrm{~Hz}$ and up to 250000 load cycles. The test results showed that the FBG sensing system is fully capable of measuring the lateral displacement of ballast under highfrequency cyclic loading. A comparison of strains obtained from FBGs installed at different depths along the ballast depth is made and the lateral strain profiles are measured. Moreover, an empirical model to convert the FBG strains to an equivalent lateral displacement of ballast is proposed to effectively use this technology in real-time monitoring of track deformations.

\section{Keywords}

ballast, cyclic loading, geogrid, FBG sensors, optical fiber, track monitoring, lateral strain profiles 


\section{Nomenclature}

$$
\begin{aligned}
D_{50} & =\text { mean particle size of ballast } \\
D_{\max } & =\text { maximum particle size of ballast } \\
\text { FBG } & =\text { fiber Bragg grating } \\
N & =\text { number of load cycles } \\
\text { SSS } & =\text { smart sensing sheet } \\
z & =\text { distance above the subballast } \\
\alpha & =\text { interface efficiency factor } \\
\varepsilon_{3} & =\text { lateral strain }
\end{aligned}
$$

\section{Introduction}

In a typical track, the large vertical axle loads combined with a relatively small horizontal confining stress leads to lateral flow of ballast and increases track settlement (Baessler and Rucker 2003; Selig and Waters 1994). The extent of lateral displacement of ballast can also be considered as an important indicator of track stability. Whilst the conventional linear variable differential transformers (LVDTs) can be conveniently used to measure lateral displacements at the ballast boundary, they run the risk of being damaged when placed within ballast. Moreover, any attempt to protect these LVDTs by steel jacketing would also reinforce the ballast and thereby alter its volumetric behavior. Therefore, it is imperative to use a thin and flexible sensing system that can record the internal displacements in ballast while maintaining the ballast properties unchanged. The optical-Fiber Bragg Grating sensors (FBGs) due to their high accuracy, reliability, and flexibility are suitable for achieving this objective. Furthermore, the polyamide coating to the optical fiber is anticipated to provide resistance against the grinding motion of particles, thus minimizing the risk of damage to the optical fibers when used in ballast. This is in contrast to the conventional strain gauges that are vulnerable to damage both during the specimen placement and the actual testing (e.g., Rowe and Gnanendran 1994).

An optical fiber is flexible and is made of glass/plastic, designed to guide light along its length by total internal reflection. The operational principle of FBGs involves monitoring of the wavelength shift in the reflected wavelength spectrum, the extent of which determines the magnitude of strain induced in the FBG. In civil engineering projects, FBGs are commonly used for structural health monitoring (Measures 2001; Connolly 2006; Liehr et al. 2008; Guo et al. 2011), embankment slope monitoring (Ho et al. 2006; Iten 2011; Xu et al. 2011), and for measuring the load transfer capacity of piles (SchmidtHattenberger et al. 2003; Lee et al. 2004a). Recently, the FBG sensors embedded on geosynthetics/geotextiles were also used to detect the soil displacement, strains induced in the pavement, and to monitor the slope stability, etc. (e.g., Liehr et al. 2008; Dijcker et al. 2011; Nöther et al. 2012). In railway engineering, the FBG sensors are generally used to monitor the strains induced in rails, and for estimating the weight and speed of trains (Lee et al. 2004b; Yoon et al. 2011). However, there is no published literature that describes the results from FBG sensors being used in examining the internal deformations in ballast. Therefore, in this study, the FBG sensors have been used to measure the lateral displacement of ballast under cyclic loading.

\section{Basic Structure of an Optical Fiber and Operating Principle of Fiber Bragg Grating Sensor}

An optical fiber is a flexible fiber made of glass or plastic, designed to guide light along its length by total internal reflection. The optical fiber consists of three parts: the core, the cladding, and the coating. The core is a cylindrical rod of dielectric material and is surrounded by a layer of material called the cladding. The cladding reduces loss of light from the core into the surrounding air and reduces scattering loss at the surface of the core. To protect the fiber from any physical damage, the cladding is enclosed in an additional layer of coating usually made of polyamide.

An FBG is formed by exposing the core of an optical fiber to an intense ultraviolet interference to cause periodic changes of the refractive index. This grating structure results in the reflection of the light at a specific narrowband wavelength, known as the Bragg wavelength. The Bragg wavelength is a function of the refractive index of the fiber core and the grating period, and this condition is represented by Eq 1. The operation principle of fiber Bragg grating (FBG) sensors involves monitoring of the wavelength shift in the reflected wavelength spectrum. When the grating is subjected to an external loading, it undergoes a change in Bragg wavelength, the extent of which determines the magnitude of strain induced in the FBG. The change in Bragg wavelength recorded by means of optical interrogator can be converted to strain in the FBG sensor by using the calibration chart supplied by the manufacturer. This is a fundamental principle that allows the fiber Bragg grating to be used as a sensor. In comparison to the conventional electric strain gauges, the use of optical-FBG sensors have a number of obvious advantages such as (a) their ability to accurately capture the strains owing to their high sensitivity and resolution, fast response, and (b) their immunity to electromagnetic and electrical signals (Zhu 2009; Mihailov 2012; Mamidi et al. 2014).

(1)

$$
\lambda_{B}=2 n_{e} \Lambda
$$

where:

$\lambda_{b}=$ is the Bragg wavelength of the FBG,

$n_{e}=$ the effective refractive index of the fiber core, and

$\Lambda=$ the grating period. 


\section{Laboratory Investigations on Geogrid-Reinforced Ballast Instrumented With FBG Sensors}

\section{TEST APPARATUS}

The tests were conducted using a large-scale modified process simulation test (MPST) apparatus, which is $800 \mathrm{~mm}$ long by $600 \mathrm{~mm}$ wide and can accommodate specimens $650 \mathrm{~mm}$ high. The central portion of one of the side walls parallel to the sleeper consists of five independent movable plates (600 by $64 \mathrm{~mm}$ ) assembled vertically with $1 \mathrm{~mm}$ gap between each plate (Indraratna et al. 2013). Figure 1(a) shows the schematic diagram of the side wall of test apparatus with five-movable plates.

\section{MATERIALS AND METHOD OF TESTING}

The test specimen comprised of a sub ballast layer of $150 \mathrm{~mm}$ at the bottom of the test chamber overlain by a $325 \mathrm{~mm}$ thick layer of ballast, conforming to AS 2758.7 (1997), compacted in three layers to a density of $1550 \mathrm{~kg} / \mathrm{m}^{3}$. The maximum particle size ( $D_{\max }$ ) of ballast used in the study is $53 \mathrm{~mm}$, with $D_{50}$ of $35 \mathrm{~mm}$, and a coefficient of uniformity, $C_{u}$, of 1.87. On the other hand, the maximum particle size $\left(D_{\max }\right)$ of sub ballast is $19 \mathrm{~mm}$, with $D_{50}$ of $0.5 \mathrm{~mm}$ and $C_{u}$ of 5 . The particle size distribution (PSD) of both the ballast and the sub ballast used in this study is shown in Fig. 1(b). An assembly of sleeper (tie) and rail section, and crib ballast up to $150 \mathrm{~mm}$ thick was placed above the loadbearing ballast (Fig. 1(c)). For reinforced specimens, a layer of geogrid was placed at either (a) $z=0 \mathrm{~mm}$ or (b) $z=65 \mathrm{~mm}$, where $z$ is the distance above the sub ballast-ballast interface. Four types of geogrids labeled G1 to G4 with different aperture sizes (Table 1) were selected based on the interface efficiency factor $(\alpha)$ obtained from direct shear testing (Indraratna et al. 2012).

\section{SMART SENSING SHEET (SSS) TO CAPTURE THE LATERAL STRAINS IN BALLAST}

To measure the variation in lateral strain along the ballast depth, a smart sensing sheet (SSS) was made by attaching the optical fibers containing FBGs to a thin and flexible polymeric sheet (Fig. 2(a)). The optical fibers and the FBG sensors were glued within the grooves of the polymeric sheet by means of Cyanoacrylate adhesive, and were left for some time for the adhesive to form a bond between fiber and the sheet. The sensing sheet was $475 \mathrm{~mm}$ long by $100 \mathrm{~mm}$ wide by $2 \mathrm{~mm}$ thick. Four FBGs with a center-to-center spacing of $81 \mathrm{~mm}$ were attached to the sensing sheet to record lateral strain in the ballast at different depths below the sleeper soffit. In case of the commercially available optical fibers with multiple FBGs installed on them, the sensors are usually spaced at a distance of $1000 \mathrm{~mm}$.

\section{FIG. 1}

(a) Schematic diagram showing the five-plate assembly of the MPST apparatus, (b) PSD of the ballast and sub ballast used in the study, and (c) photograph showing the ballast specimen instrumented with FBG sensors ready for testing.

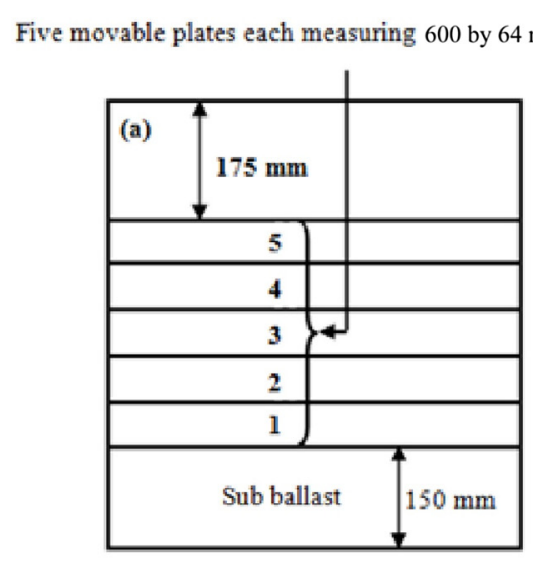

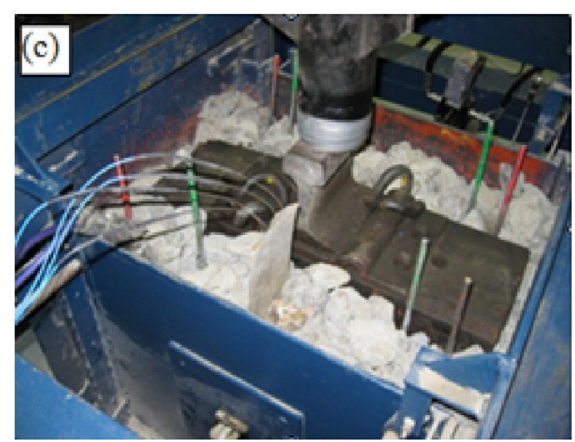


TABLE 1 Physical characteristics and technical specifications of the geogrids used in the current study.

\begin{tabular}{|c|c|c|c|c|c|c|c|c|c|}
\hline \multirow[b]{2}{*}{ Geogrid Type } & \multirow[b]{2}{*}{ Aperture Shape } & \multicolumn{2}{|c|}{ Aperture Size (mm) } & \multicolumn{2}{|c|}{ Rib Thickness (mm) } & \multicolumn{2}{|c|}{$T_{u l t}^{\mathrm{a}}(\mathrm{kN} / \mathrm{m})$} & \multicolumn{2}{|c|}{$J_{\mathrm{s}}{ }^{\mathrm{b}}(2 \%$ Strain $)(\mathrm{kN} / \mathrm{m})$} \\
\hline & & $\mathrm{MD}$ & CMD & $\mathrm{MD}$ & CMD & $\mathrm{MD}$ & CMD & $\mathrm{MD}$ & CMD \\
\hline G1 & Square & 38 & 38 & 2.2 & 1.3 & 30 & 30 & 525 & 525 \\
\hline G2 & Triangle & 36 & 36 & 2.0 & 2.0 & 19 & 19 & 230 & 230 \\
\hline G3 & Square & 65 & 65 & 1.7 & 1.5 & 30 & 30 & 550 & 600 \\
\hline G4 & Rectangle & 44 & 42 & 1.0 & 1.0 & 30 & 30 & 500 & 500 \\
\hline
\end{tabular}

${ }^{a}$ Ultimate tensile strength (manufacturer supplied values).

${ }^{\mathrm{b}}$ Secant tensile stiffness (manufacturer supplied values); $\mathrm{MD}=$ machine direction and $\mathrm{CMD}=$ cross machine direction.

As one of the aims of the current study is to compare the lateral strain of ballast at different depths within a $325 \mathrm{~mm}$ thick ballast layer, it is impractical to adopt fibers with multiple FBGs embedded on them, and hence four distinct FBGs are used. While the custom made fibers can have the sensors placed at distances closer than $1000 \mathrm{~mm}$, it increases the cost of production substantially especially for spacing of $81 \mathrm{~mm}(<100 \mathrm{~mm})$ used in this study. Therefore, owing to the budget limitations, the current configuration of using four cables with only one FBG on each of them was considered to be a low-cost solution. Each optical fiber used in the study had an FBG sensor of length $10 \mathrm{~mm}$ embedded on the core of the fiber, and was coated with polyamide as a protection to the sensor and the fiber itself. The location of the FBGs above the sub ballast, as well as their wavelengths, is summarized in Table 2. The SSS was installed in the MPST apparatus with its width parallel to the movable sidewall so that the lateral flow of ballast could be measured (Fig. 2(b)). The $100 \mathrm{~mm}$ width of the sensing sheet corresponds to about $2.85 D_{50}$, thus ensuring that the strains recorded from the FBG sensors represent the average lateral displacement of ballast. A dynamic 4-channel optical sensing interrogator (Si425) was employed for the demodulation of the FBGs. The FBG data was recorded at a frequency of $1.25 \mathrm{~Hz}$. An Ethernet connection was used for the automatic data communication between the interrogator and the computer (Micron Optics Inc. 2007).

A vertical stress of $460 \mathrm{kPa}$ that corresponds to an axle load of $225 \mathrm{kN}$ moving at a speed of $146 \mathrm{~km} / \mathrm{h}$ was applied by means of a dynamic actuator (Esveld 2001; Atalar et al. 2001;

FIG. 2

(a) Positioning of FBG sensors on the SSS, (b) placement location of the 'SSS embedded with FBG sensors' within the test tank, and (c) schematic diagram showing the track geometry and the portion of track along with the boundary conditions simulated in the study (modified after Indraratna et al. (2013)).

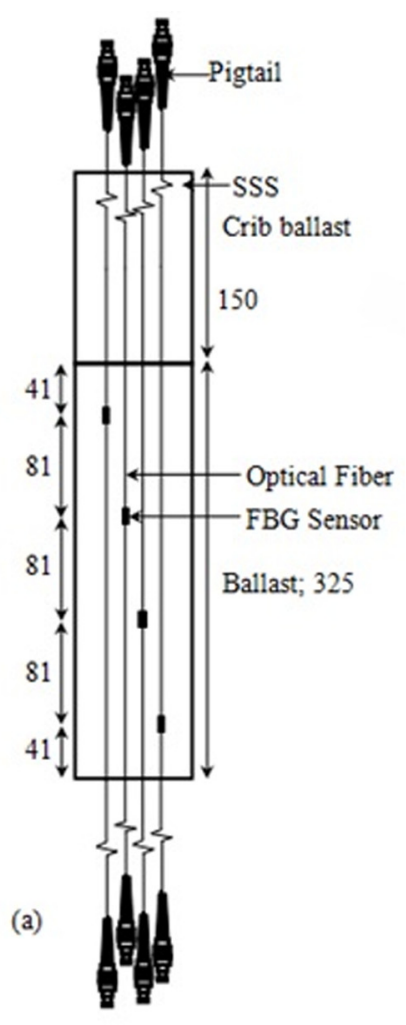

Longitudinal direction; $\varepsilon_{2}=0$ (Plane strain conditions)

(c)

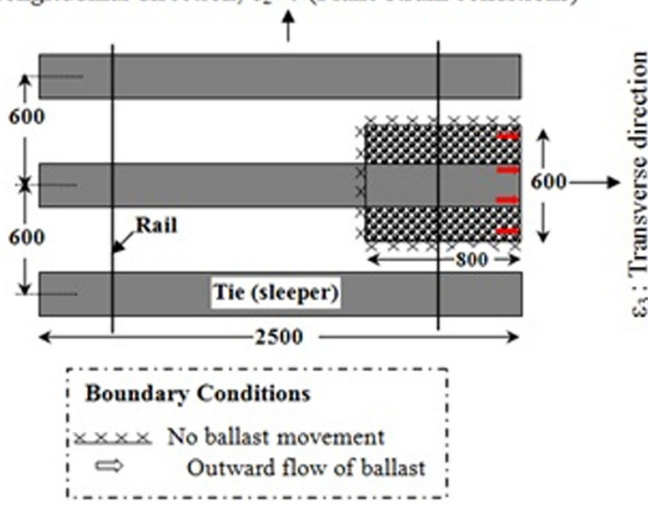

All dimensions are in $\mathrm{mm}$ 
TABLE 2 Placement location of FBG sensors above the sub ballast along with their wavelengths.

\begin{tabular}{|c|c|c|c|c|c|}
\hline \multirow[b]{2}{*}{ Sensor Number } & \multirow[b]{2}{*}{ Position Above Sub Ballast (mm) } & \multicolumn{4}{|c|}{ Wavelength (nm) } \\
\hline & & $\mathrm{UR}, \mathrm{G} 3^{*}, \mathrm{G} 1^{*}$ & $\mathrm{G}^{+}, \mathrm{G}^{+}{ }^{+}$ & $\mathrm{G} 4^{+}, \mathrm{G} 2^{*}$ & $\mathrm{G} 3^{+}, \mathrm{G} 4^{*}$ \\
\hline FBG4 & 284 & 1535 & 1535 & 1535 & 1535 \\
\hline FBG3 & 203 & 1535 & 1555 & 1540 & 1535 \\
\hline FBG2 & 122 & 1545 & 1560 & 1550 & 1550 \\
\hline FBG1 & 41 & 1555 & 1560 & 1560 & 1555 \\
\hline
\end{tabular}

Note: geogrid placement position: ${ }^{*}$ sub ballast-ballast interface (i.e., $z=0 \mathrm{~mm}$ ); ${ }^{+} 65 \mathrm{~mm}$ above the subballast (i.e., $z=65 \mathrm{~mm}$ ).

Indraratna et al. 2011). The detailed calculations on the vertical stress considering the axle load and the wheel diameter are explained in Indraratna et al. (2011). Several past studies also used similar values of vertical stress on ballast for Australian track conditions (e.g., Ionescu et al. 1998; Indraratna et al. 2005,2011). A lateral pressure of $10 \mathrm{kPa}$ was applied onto the side wall comprising of five movable plates. The value of confining pressure adopted here falls within the range of in situ confining pressure of $10-30 \mathrm{kPa}$ measured earlier by Indraratna et al. (2010,2011). Le Pen (2008), and Le Pen and Powrie (2011) also reported similar values of confining pressure considering the effect of the shoulder ballast. In this context, the application of lateral pressure of $10 \mathrm{kPa}$ on the movable plates is realistic.
The lateral movement of plates was recorded by the LVDTs. Under track operating conditions, the lateral spreading of ballast is in the outward direction (parallel to ties) with almost a zero lateral movement along the centerline of the track. Therefore, by exploiting symmetry, only one of the two side walls (i.e., the modified wall with five movable plates) was allowed to move laterally, while the other side wall was held fixed. Similarly, the other two boundaries of the apparatus perpendicular to the rail were also fixed to simulate the plane strain conditions in the longitudinal direction (Hussaini 2013; Indraratna et al. 2013) (Fig. 2(c)). Tests were conducted at a loading frequency of $20 \mathrm{~Hz}$ and up to 250000 load cycles. Figure 1(c) shows the ballast specimen instrumented with FBGs ready for testing.
FIG. 3

Variation of lateral strains in unreinforced and geogrid-reinforced ballast ( $\mathrm{G} 3$ at $\mathrm{z}=0 \mathrm{~mm}$ ) with $\mathrm{N}$ in FBG sensors located at (a) $284,(b)$ 203, (c) 122, and (d) $41 \mathrm{~mm}$ above the sub ballast.
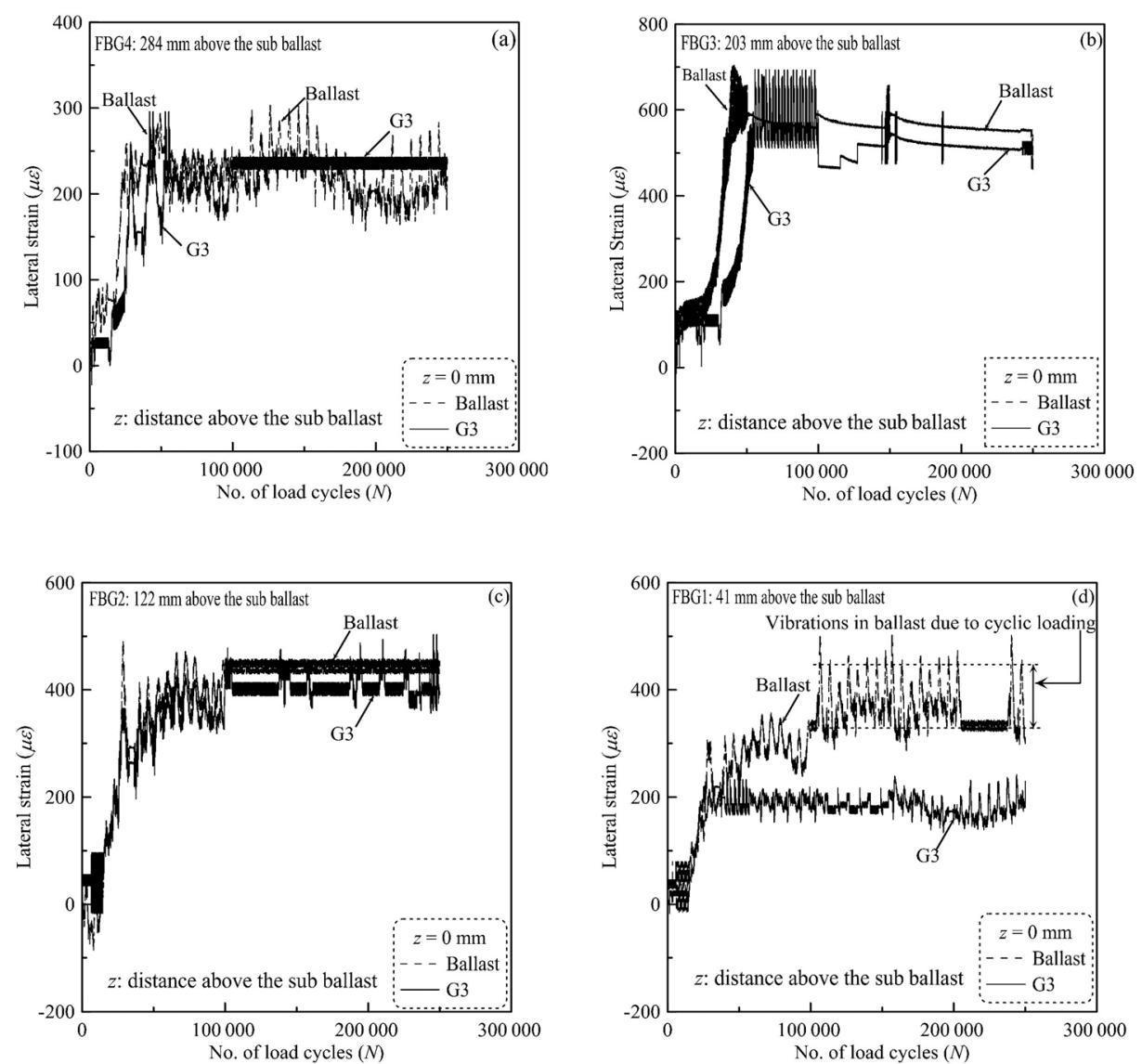


\section{Experimental Results and Discussion}

\section{THE VARIATION OF LATERAL STRAINS ALONG THE BALLAST DEPTH WITH NUMBER OF LOAD CYCLES (N)}

The variation of FBG based lateral strains with $N$ for unreinforced and ballast reinforced with geogrid G3 (placed at $z=0$ and $z=65 \mathrm{~mm}$ ) is shown in Figs. 3 and $\mathbf{4}$, respectively. It is seen that most of the FBG strains develop during the initial 50000 load cycles, indicating that intense lateral spread of particles occurs during this loading regime for both the geogrid placement positions. The evolution pattern of FBG strain with $N$ captured here is similar to that reported in the past by several researchers based on the conventional data acquisition techniques (e.g., Raymond and Bathurst 1994; Lackenby et al. 2007; Aursudkij et al. 2009; Indraratna et al. 2010,2013). This clearly highlights the ability of FBG sensing system in accurately capturing the strain evolution pattern in ballast at both initial and final stages of loading. Although the magnitude of strains changes from one location to another along the ballast depth, the variation of FBG strains follows a similar trend with $N$. The FBG sensing system has also successfully captured the effect of geogrid in reducing the lateral strains in ballast as evident from
Fig. $\mathbf{3}(c)$ and $\mathbf{3}(d)$. Here, the extent of reduction in strains due to the geogrid placed at $z=0 \mathrm{~mm}$ is significant for FBG-1 (Fig. $\mathbf{3}(\boldsymbol{d})$ ) and is marginal for FBG-2 (Fig. $\mathbf{3}(\mathbf{c})$ ), as FBG-1 is nearer to the placement position of geogrid. In Figs. 3(a) and 4(a), a portion of the FBG data corresponding to unreinforced ballast and that of geogrid G3 merges with each other, highlighting that the effect of geogrid is insignificant at a distance of $284 \mathrm{~mm}$ above the sub ballast. A further comparison of Figs. 3 and 4 reveals that a higher reduction in the lateral strains occurs for $z=65 \mathrm{~mm}$ (Fig. 4), which is indicative of a greater interaction between the geogrid and the ballast. These findings based on the FBG sensors are in uniformity with earlier studies that reported the effect of geogrid to be higher when placed within ballast (Chen et al. 2013; Hussaini 2013; Indraratna et al. 2013). Figure $\mathbf{4}(c)$ and $\mathbf{4}(d)$ confirm the consistency in results from the original and replicate tests that match closely with each other. This consistency in results, together with the similar strain evolution pattern described earlier, corroborates the efficacy of FBG sensors in measuring the internal deformations in ballast.

In addition to the macroscopic behavior of ballast, the FBG sensors also captured the vibrations induced in ballast due to high-frequency cyclic loading (Fig. 3(d)). This ability of the FBG

\section{FIG. 4}

Variation of lateral strains in unreinforced and geogrid-reinforced ballast ( $\mathrm{G} 3$ at $\mathrm{z}=65 \mathrm{~mm}$ ) with $\mathrm{N}$ in FBG sensors located at (a) 284, (b) 203, (c) 122, and (d) $41 \mathrm{~mm}$ above the sub ballast.
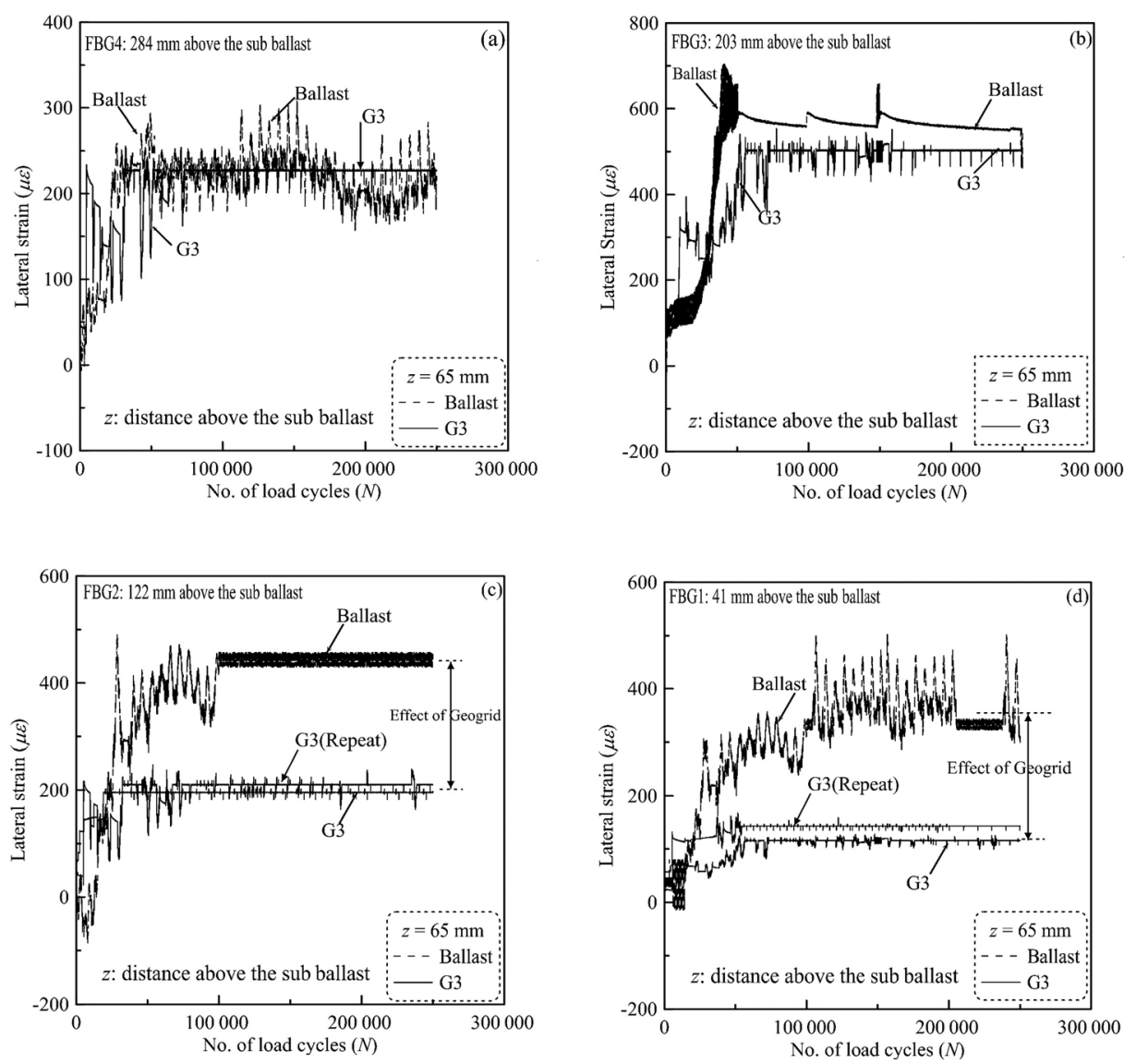
sensing system to record the vibrations in ballast can be primarily attributed to the higher sensitivity and resolution, faster response of FBG sensors, and their immunity to electromagnetic and electrical signals. The fluctuations resulting from vibration indicate that at a micro-scale, ballast undergoes both inward and outward movement under track operating conditions. Nevertheless, the overall particle flow is essentially in an outward direction that eventually deteriorates the track alignment. Figures $\mathbf{3}(d)$ and $\mathbf{4}(d)$ further reveal that the geogrid not only minimizes the lateral displacement, but also reduces the magnitude of vibrations when compared to unreinforced ballast. The occasional sharp rise and fall in FBG strain (Figs. 3(b) and $\mathbf{3}(c)$ ) is consistent with the research results available in the literature (e.g., Zhu 2009; Weng and Wang 2011) and may be attributed to the localized rearrangement of particles during the loading. Similarly, the absence of fluctuations in the FBG data in Figs. $\mathbf{3}(b)$ and $\mathbf{4}(b)$ beyond a certain number of load applications may be attributed to the lack of ballast movement in the vicinity of FBG due to strong inter-particle interlocking in a localized zone.

\section{LATERAL STRAIN PROFILES ALONG THE BALLAST DEPTH}

One of the objectives of the current study is also to compare the lateral strain of ballast at different depths within a $325-\mathrm{mm}$ thick ballast layer. In this context, the lateral strain profiles based on the average FBG strains were plotted for the unreinforced ballast and reinforced specimens with geogrids G3 and G4, for 250000 load cycles (Fig. 5(a)). The FBG data suggest that the lateral strains in the immediate vicinity of the geogrid are smaller than the unreinforced ballast, and the effect of reinforcement decreases with vertical distance away from the geogrid (Fig. 5(a)). Given the similarity of these observations to a previous study (Indraratna et al. 2013), although based on different measuring techniques, the observations highlight the ability of FBGs to capture the lateral movement of ballast adequately.

\section{COMPARISON OF LATERAL STRAIN PROFILES UNDER THE RAIL AND BENEATH THE SLEEPER EDGE}

The lateral strain profiles of ballast under the rail, based on FBG data, are compared with those of ballast beneath the sleeper edge, presented by Indraratna et al. (2013) (Fig. 5(b)). Although a direct comparison between the lateral strain profiles established at these two track sections is not possible due to the different techniques adopted for measuring the particle movement, the strain profiles at these two locations still compare well with each other. In the absence of any other study describing the lateral strain profiles in ballast by using the FBG sensors or other techniques, this comparison with Indraratna et al. (2013) validates the findings of the current study. However, unlike the strain profiles beneath the sleeper edge, those under the rail show some fluctuations, which could be attributed to the
FIG. 5 (a) Lateral strain profile along the ballast depth as obtained from the strain in FBG sensors, and (b) comparison of lateral strain profiles from the FBG data (under the rail) and the wall movement (beneath the sleeper edge) in case of unreinforced ballast and that reinforced with geogrid G4.


localized nature of FBG data. This is because the FBG strains represent the particle spread at a small section within the test chamber, as the width of the SSS is only $100 \mathrm{~mm}$ compared to the total ballast width of $600 \mathrm{~mm}$. On the other hand, the lateral displacement of particles measured beneath the sleeper-edge from the sidewall movement corresponds to the entire ballast width. Moreover, the lateral strain profiles under the rail are based on data from four FBGs rather than the data from five movable plates in the case of strain profiles beneath the sleeper 
FIG. 6 Conversion of strains in FBG sensors to equivalent lateral displacement.



edge. It is thus envisaged that the use of multiple sensing sheets (instrumented with more than four FBGs) would provide a more accurate record of the lateral movement of particles.

\section{CONVERSION OF STRAINS IN FBG SENSORS TO EQUIVALENT LATERAL DISPLACEMENT}

The FBG strains indicate the tendency of ballast to spread laterally. Therefore, it is essential to convert the FBG strains to the equivalent lateral displacement of ballast so that the current state of the track could be assessed. It is well known that in a typical track, the sleeper-ballast contact pressure is mostly concentrated in the region corresponding to about one-third the length of the sleeper from either end (Jeffs and Tew 1991; Atalar et al. 2001). In other words, the magnitude of sleeperballast contact pressure immediately under the rail and beneath the sleeper edge is necessarily the same. In this context, the extent of lateral displacement of ballast under the rail and sleeper edge can be assumed to be identical. Therefore, the FBG strains $\left(\varepsilon_{3}\right)$ are plotted with respect to the lateral displacement of ballast beneath the sleeper edge (Fig. 6). Here, the data from FBG-4 (topmost sensor) and FBG-1 (bottom sensor) are compared with the movement of top and bottom plates, respectively. On the other hand, the data from FBG-3 and FBG-2 are compared with the average of movement of plates 3-4 and 2-3, respectively. It is seen from Fig. 6 that the average FBG strains based on the laboratory data on unreinforced ballast and of specimens reinforced with geogrids $\mathrm{Gl}^{+}$, $\mathrm{G}^{*}$, and $\mathrm{G} 3^{+}$, follow a linear relationship with the lateral displacement (Eq 2).

(2) Lateral displacement $(\mathrm{mm})=0.042 \times \epsilon_{3}(\mu \epsilon)$
FIG. 7 (a) Comparison between the predicted and measured lateral displacements with number of load cycles in case of ballast reinforced with geogrid $\mathrm{G} 4$, and (b) the measured lateral displacements versus the empirical predictions to validate the empirical model.


\section{VALIDATION OF THE CORRELATION BETWEEN STRAINS IN THE FBG SENSORS AND THE LATERAL DISPLACEMENT OF BALLAST}

To validate the correlation between FBG strain and the lateral movement of ballast, the equivalent lateral displacement predicted by Eq 2 is compared with the experimental measurements for ballast reinforced with geogrid G4 (Fig. 7(a)). It is evident that the empirical predictions of lateral displacement agree reasonably well with the laboratory measurements of the sidewall movement. Figure $\mathbf{7}(\boldsymbol{b})$ presents the measured lateral displacements plotted in comparison with the empirical predictions, showing an acceptable agreement along the $45^{\circ}$ line. An 
independent set of data from tests on ballast reinforced with $\mathrm{G} 2^{*}, \mathrm{G} 4^{*}$, and $\mathrm{G} 4^{+}$was used to validate the model $\left(^{*}\right.$ and ${ }^{+}$ indicate geogrid at $z=0$ and $65 \mathrm{~mm}$, respectively). In a practical sense, this empirical model assists in converting the FBG strains to the equivalent lateral displacement of ballast.

\section{Limitations of the Study}

In this paper, an attempt was made to assess the potential of an optical-FBG sensing system in capturing the lateral deformation behavior of ballast. An empirical equation was developed (Eq 2) between the measured displacement of plates and strains from FBG sensors. However, additional large-scale laboratory testing considering different ballast and loading conditions has to be carried out for developing a robust equation for the practicing engineers. Moreover, advanced numerical simulations have to be carried out considering real boundary and loading conditions before this optical sensing technology could be recommended for the field application.

\section{Conclusions}

The results from the large-scale tests using the MPST apparatus indicated that the FBG sensors successfully measured the lateral displacement of ballast and also captured the vibrations in ballast during cyclic loading. It was also shown that the shape of the FBG-based lateral strain profiles agreed reasonably well with those established from the movement of sidewall of the MPST apparatus. Furthermore, the lateral strain profiles determined by FBGs reconfirmed that the effect of reinforcement was predominant in its immediate vicinity, but decreased rapidly with vertical distance away from the geogrid. The test results revealed that a higher reduction in the lateral strains occurs when the geogrid is placed at $z=65 \mathrm{~mm}$ in comparison to $z=0 \mathrm{~mm}$ ( $z$ is the distance above the sub ballast-ballast interface). An empirical relationship was presented that could convert the FBG strains to an equivalent lateral displacement.

This current study, albeit preliminary, encourages the use of FBG sensors in railway applications as a track monitoring system. The FBG strains would serve as an indicator of whether there is a necessity to initiate ballast maintenance. However, further laboratory testing and field trials are needed to develop the requisite field standards to use the FBG sensing systems in monitoring the ballast performance.

\section{ACKNOWLEDGMENTS}

The writers would like to thank CRC for Rail Innovation (established and supported under the Australian Government's Cooperative Research Centres program) for the funding of this research. The assistance of Technical Officers at the Centre of Geomechanics and Railway Engineering, University of Wollongong, in the laboratory tests is highly appreciated. Our thanks are also due to the anonymous reviewers for their valuable comments and suggestions to improve the quality of the paper.

\section{References}

AS 2758.7, 1997: Aggregates and Rock for Engineering Purposes, Part 7: Railway Ballast, Standards Association of Australia, Sydney, Australia.

Atalar, C., Das, B. M., Shin, E. C., and Kim, D. H., 2001, "Settlement of Geogrid Reinforced Railroad Bed Due to Cyclic Load," Proceedings of 15th International Conference on Soil Mechanics and Geotechnical Engineering, Istanbul, Turkey, Aug 27-31, Taylor \& Francis, London, pp. 2045-2048.

Aursudkij, B., McDowell, G. R., and Collop, A. C., 2009, "Cyclic Loading of Railway Ballast Under Triaxial Conditions and in a Railway Test Facility," Gran. Matter, Vol. 11, No. 6, pp. 391-401.

Baessler, M. and Rucker, W., 2003, “Track Settlement Due to Cyclic Loading With Low Minimum Pressure and Vibrations," System Dynamics and Long-Term Behaviour of Railway Vehicles, Track and Subgrade, K. Popp and W. Schiehlen, Eds., Springer, Berlin, pp. 337-356.

Chen, C., McDowell, G. R., and Thom, N. H., 2013, "Discrete Element Modelling of Cyclic Loads of Geogrid-Reinforced Ballast Under Confined and Unconfined Conditions," Geotext. Geomembr., Vol. 35, No. 12, pp. 76-86.

Connolly, C., 2006, "Fibre-Optic-Based Sensors Bring New Capabilities to Structural Monitoring," Sens. Rev., Vol. 26, No. 3, pp. 236-243.

Dijcker, R., Wijk, M. V. D., Artières, O., Dortland, G., and Lostumbo, J., 2011, "Geotextile Enabled Smart Monitoring Solutions for Safe and Effective Management of Tailings and Waste Sites, Two Case Studies: Volgermeerpolder (The Netherlands) and Suncor (Canada)," presented at the Tailings and Mine Waste Conference, Vancouver, BC, Nov 6-9, Norman B. Keevil Institute of Mining Engineering, Vancouver, BC, pp. 1-8.

Esveld, C., 2001, Modern Railway Track, MRT-Productions, Zaltbommel, the Netherlands.

Guo, H., Xiao, G., Mrad, N., and Yao, J., 2011, "Fiber Optic Sensors for Structural Health Monitoring of Air Platforms," Sensors, Vol. 11, No. 4, pp. 3687-3705.

Ho, Y. T., Huang, A. B., and Lee, J. T., 2006, "Development of a Fibre Bragg Grating Sensored Ground Movement Monitoring System," Meas. Sci. Technol., Vol. 17, No. 7, pp. 1733-1740.

Hussaini, S. K. K., 2013, "An Experimental Study on the Deformation Behaviour of Geosynthetically Reinforced Ballast," Ph.D. thesis, University of Wollongong, Wollongong, Australia.

Indraratna, B., Hussaini, S. K. K., and Vinod, J. S., 2012, "On the Shear Behavior of Ballast-Geosynthetic Interfaces," ASTM Geotech. Test. J., Vol. 35, No. 2, pp. 305-312.

Indraratna, B., Hussaini, S. K. K., and Vinod, J. S., 2013, "The Lateral Displacement Response of Geogrid-Reinforced Ballast Under Cyclic Loading," Geotext. Geomembr., Vol. 39, pp. 20-29.

Indraratna, B., Nimbalkar, S., Christie, D., Rujikiatkamjorn, C., and Vinod, J. S., 2010, "Field Assessment of the Performance 
of a Ballasted Rail Track With and Without Geosynthetics," J. Geotech. Geoenviron. Eng., Vol. 136, No. 7, pp. 907-917.

Indraratna, B., Salim, W., and Rujikiatkamjorn, C., 2011, Advanced Rail Geotechnology-Ballasted Track, CRC Press, Boca Raton, FL.

Indraratna, B., Shahin, M. A., and Salim, M. W., 2005, "Use of Geosynthetics for Stabilising Recycled Ballast in Railway Track Substructures," presented at the North American Geosynthetics Society (NAGS)-Geosynthetics Institute (GSI) Conference, Las Vegas, NV, Dec 14-16, NAGS, Albany, NY, pp. 1-15.

Ionescu, D., Indraratna, B., and Christie, H. D., 1998 , "Behaviour of Railway Ballast Under Dynamic Loads," Proceedings of the 13th Southeast Asian Geotechnical Conference and the Fourth International Conference on Tropical Soils, Taipei, Taiwan, Nov 16-20, Southeast Asian Geotechnical Society, Taiwan, pp. 69-74.

Iten, M., 2011, "Novel Applications of Distributed Fiber-Optic Sensing in Geotechnical Engineering," Ph.D. thesis, ETH Zürich, Zürich, Switzerland.

Jeffs, T. and Tew, G. P., 1991, A Review of Track Design Procedures: Sleepers and Ballast, Railways of Australia BHP Research, Melbourne Laboratories, Melbourne, Australia.

Lackenby, J., Indraratna, B., McDowell, G., and Christie, D., 2007, "Effect of Confining Pressure on Ballast Degradation and Deformation Under Cyclic Triaxial Loading," Geotechnique, Vol. 57, No. 6, pp. 527-536.

Le Pen, L., 2008, "Track Behaviour: The Importance of the Sleeper to Ballast Interface," Ph.D. thesis, University of Southampton, Southampton, UK.

Le Pen, L. M. and Powrie, W., 2011, "Contribution of Base, Crib and Shoulder Ballast to the Lateral Sliding Resistance of Railway Track: A Geotechnical Perspective," Proc. Inst. Mech. Eng. Part F, Vol. 225, No. 2, pp. 113-128.

Lee, W., Lee, W. J., Lee, S. B., and Salgado, R., 2004a, "Measurement of Pile Load Transfer Using the Fiber Bragg Grating Sensor System," Can. Geotech. J., Vol. 41, No. 6, pp. 1222-1232.

Lee, K. Y., Lee, K. K., and Ho, S. L., 2004b, "Exploration of Using FBG Sensor for Axle Counter in Railway Engineering," WSEAS Trans. Syst., Vol. 6, No. 3, pp. 2440-2447.

Liehr, S., Lenke, P., Krebber, K., Seeger, M., Thiele, E., Metschies, H., Gebreselassie, B., Münich, J. C., and Stempniewski, L., 2008, "Distributed Strain Measurement With Polymer Optical Fibers Integrated Into Multifunctional Geotextiles," Proc. SPIE, Vol. 7003, 700302.

Mamidi, V. R., Kamineni, S., Ravinuthala, L. N. S. P., Madhuvarasu, S. S., Thumu, V. R., Pachava, V. R., and Putha, K., 2014, "Fiber Bragg Grating-Based High Temperature Sensor and its Low Cost Interrogation System With Enhanced Resolution," Opt. Appl., Vol. 44, No. 2, pp. 299-308.

Measures, R. M., 2001, Structural Monitoring With Fiber Optic Technology, Academic Press, New York.

Micron Optics, Inc., 2007, "Si 425: Optical Sensing Interrogator Instruction Manual,” Atlanta, USA.

Mihailov, S. J., 2012, "Fiber Bragg Grating Sensors for Harsh Environments," Sensors (Basel), Vol. 12, No. 2, pp. 1898-1918.

Nöther, N., Glötzl, R., Vollmert, L., Ehrenberg, H., Weisemann, U., Großmann, S., and Oehmichen, R., 2012, "Displacement Monitoring in Geotechnical Applications Using Optical Fiber Sensors in Geosynthetics," presented at the 6th European Workshop on Structural Health Monitoring, Dresden, Germany, July 2-6, German Society for Nondestructive Testing, Berlin, pp. 1-7.

Raymond, G. P. and Bathurst, R. J., 1994, "Repeated-Load Response of Aggregates in Relation to Track Quality Index," Can. Geotech. J., Vol. 31, No. 4, pp. 547-554.

Rowe, R. K. and Gnanendran, C. T., 1994, "Geotextile Strain in a Full Scale Reinforced Test Embankment," Geotext. Geomembr., Vol. 13, No. 12, pp. 781-806.

Selig, E. T. and Waters, J. M., 1994, Track Geotechnology and Substructure Management, Thomas Telford Services Ltd., London.

Schmidt-Hattenberger, C., Straub, T., Naumann, M., Borm, G., Lauerer, R., Beck, C., and Schwarz, W., 2003, "Strain Measurements by Fiber Bragg Grating Sensors for In-Situ Pile Loading Tests," Proc. SPIE, Vol. 5050, pp. 289-294.

Weng, X. and Wang, W., 2011, "Influence of Differential Settlement on Pavement Structure of Widened Roads Based on Large-Scale Model Test," J. Rock Mech. Geotech. Eng., Vol. 3, No. 1, pp. 90-96.

Xu, D. S., Yin, J. H., Cui, P., Pei, H. F., Zhu, H. H., and Hong, C. Y., 2011, "Monitoring and Analysis of Internal Displacements of a Slope and Relationship With Rainfall Infiltration," Proceedings of 3rd International Postgraduate Conference on Infrastructure and Environment, Hong Kong, July $12-14$, S. J. Liu, Ed., The Hong Kong Polytechnic University, Hong Kong, pp. 117-123.

Yoon, H.-J., Song, K.-Y., Kim, J.-S., and Kim, D.-S., 2011, "Longitudinal Strain Monitoring of Rail Using a Distributed Fiber Sensor Based on Brillouin Optical Correlation Domain Analysis," NDT\&E Int., Vol. 44, No. 7, pp. 637-644.

Zhu, H., 2009, "Fiber Optic Monitoring and Performance Evaluation of Geotechnical Structures," Ph.D. thesis, The Hong Kong Polytechnic University, Hong Kong. 